\title{
High Degree Atrioventricular Block Complicated Cardiac Sarcoidosis: Case Report
}

\author{
Malka Yahalom ${ }^{1 *}$, Ofir Koren ${ }^{1,2}$, Yoav Turgeman ${ }^{1,2}$ \\ ${ }^{1}$ Heart Institute, Emek Medical Center, Afula, Israel \\ ${ }^{2}$ Bruce Rappaport, Faculty of Medicine, Technion-Israel Institute of Technology, Haifa, Israel \\ Email: *malka8@netvision.net.il
}

How to cite this paper: Yahalom, M., Koren, O. and Turgeman, Y. (2018) High Degree Atrioventricular Block Complicated Cardiac Sarcoidosis: Case Report. World Journal of Cardiovascular Surgery, 8, 157163.

https://doi.org/10.4236/wjcs.2018.89015

Received: May 8, 2017

Accepted: September 15, 2018

Published: September 18, 2018

Copyright (c) 2018 by authors and Scientific Research Publishing Inc. This work is licensed under the Creative Commons Attribution International License (CC BY 4.0)

http://creativecommons.org/licenses/by/4.0/

\begin{abstract}
Cardiac Sarcoidosis (CS) is a rare and deceptive disease affecting young adults with catastrophic results including life threatening arrhythmia, congestive heart failure and even sudden death as the initial presentation. CS has been linked to a significant high morbidity \& mortality. We present two patients: The first patient with an initial cardiac event that led us to a diagnosis of Pulmonary and Cardiac Sarcoidosis. A second patient, who was diagnosed initially with pulmonary Sarcoidosis, presented with a severe heart conduction abnormality. Both patients were successfully treated with permanent pacemakers. The dual purpose of our study is first to emphasize the importance of follow up on patients with Non-Cardiac Sarcoidosis for cardiac involvement and secondly to increase awareness of CS as part of a differential diagnosis among young adults with unexplained arrhythmia.
\end{abstract}

\section{Keywords}

Heart Conduction System, Complete AV Block, Pulmonary Sarcoidosis, Cardiac Sarcoidosis

\section{Introduction}

Sarcoidosis is a rare, multisystem, granulomatous disease of unknown etiology that most often affects the lungs (over 90\%), skin, eyes, and lymphoreticular system [1] [2]. Non-caseating granulomas are the pathological hallmark of Sarcoidosis [3]. The disease manifests itself worldwide, without regard to gender, age and ethnicity [4] [5] [6] [7]. Although it usually develops before the age of 50, the incidence rate displays a biphasic pattern with the first peak between the ages of 25 - 39 and the second between the ages of 60 - 64 [8] [9]. Cardiac involvement in Sarcoidosis occurs in $20 \%-30 \%$ of the patients [10]. 
Despite its association with high rates of mortality, sole involvement of the heart is estimate at being $2 \%-5 \%$ of the documented cases, and has the lowest incident manifestation. CS manifestations include conduction disorders, arrhythmias, Atrial and Ventricular arrhythmias, congestive heart failure, valvular pathology, pericardial effusions and sudden cardiac death [11] [12].

The most frequently involved region is the left ventricular free wall, followed by the interventricular septum, often with involvement of the conducting system. The most specific characteristic feature of CS in echocardiogram is interventricular thinning [13].

Less than $5 \%$ of patients die from Sarcoidosis. While Sarcoidosis is not commonly fatal, cardiac involvement may be responsible for more than two-thirds of deaths. In Japan, cardiac involvement is more common in older women and responsible for as many as $85 \%$ of deaths [14].

Cardiac involvement in patients with Sarcoidosis is increasingly recognized as being associated with a poor prognosis [15].

Early screening for cardiac involvement in patients with known Sarcoidosisin other organ systems is crucial, especially because sudden death may be the first manifestation of CS and prompt treatment can reduce its risk [16].

It is recommended to carry out a detailed clinical history to identify cardiac symptoms (including syncope, pre-syncope or palpitations), a 12-lead electrocardiogram (ECG) and an echocardiogram.

Further screening is advised if any of the initial screening investigations yield an abnormality; cardiovascular magnetic resonance (CMR) or fluorodeoxyglucose positron emission tomography (FDG-PET) [17] [18].

Screening for cardiac involvement in specific clinical presentations in patients without known Sarcoidosis, can also identify CS patients early in their disease course. A clinical diagnosis of CS is critically important in the planning of therapeutic strategy.

\section{Patients and Materials}

We describe two CS patients with an initial presentation of a heart conduction abnormality.

\subsection{Case I}

A 43-year-old male, without known chronic illnesses brought to Emergency Room after syncope. The patient denied preliminary complains, previously similar events or decrease in functional capacity. Initial ECG showed prolonged non-conducted $\mathrm{P}$ waves indicating complete atrioventricular block (Figure 1-Strip ECG shows Prolonged Non-Conducted P waves (black Arrows) indicate complete atrioventricular block). Temporarily pacemaker was placed. A quick preliminary inquiry eliminates an ischemic cause and electrolytes imbalance. On chest X-Ray there was a suspicion of fullness on hila of the lungs. Computed tomography of the chest reveled bilateral mediastinal lymph nodes enlargement (Figure 2-CT scan of the chest showing bilateral lymph nodes 


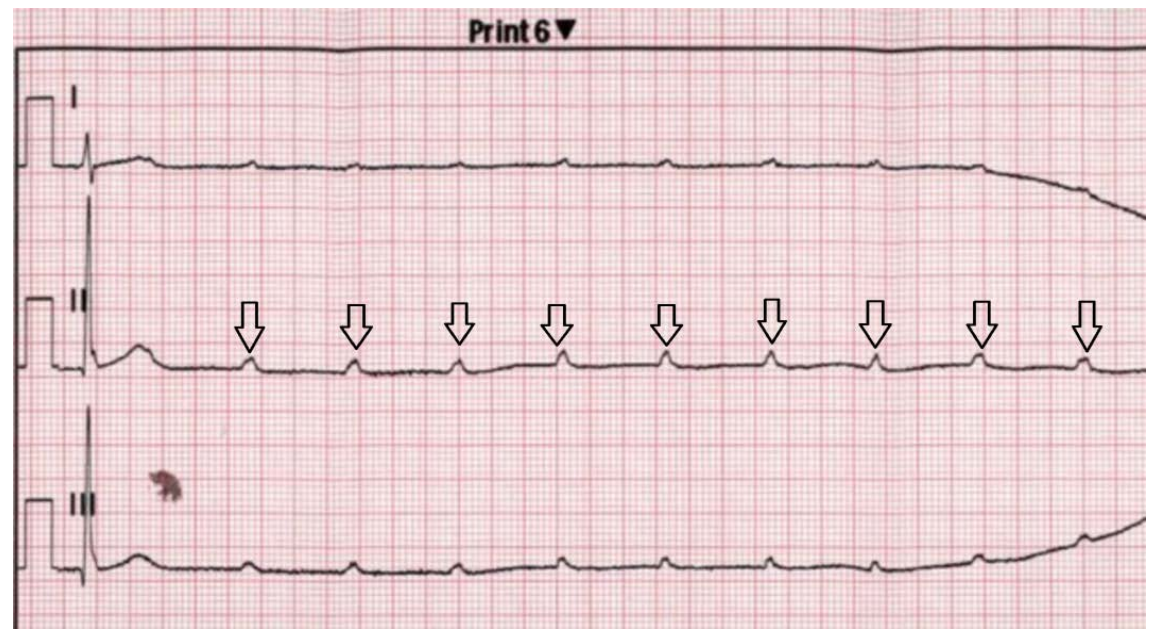

Figure 1. Strip ECG shows Prolonged Non-Conducted P waves (black Arrows) indicate complete atrioventricular block.

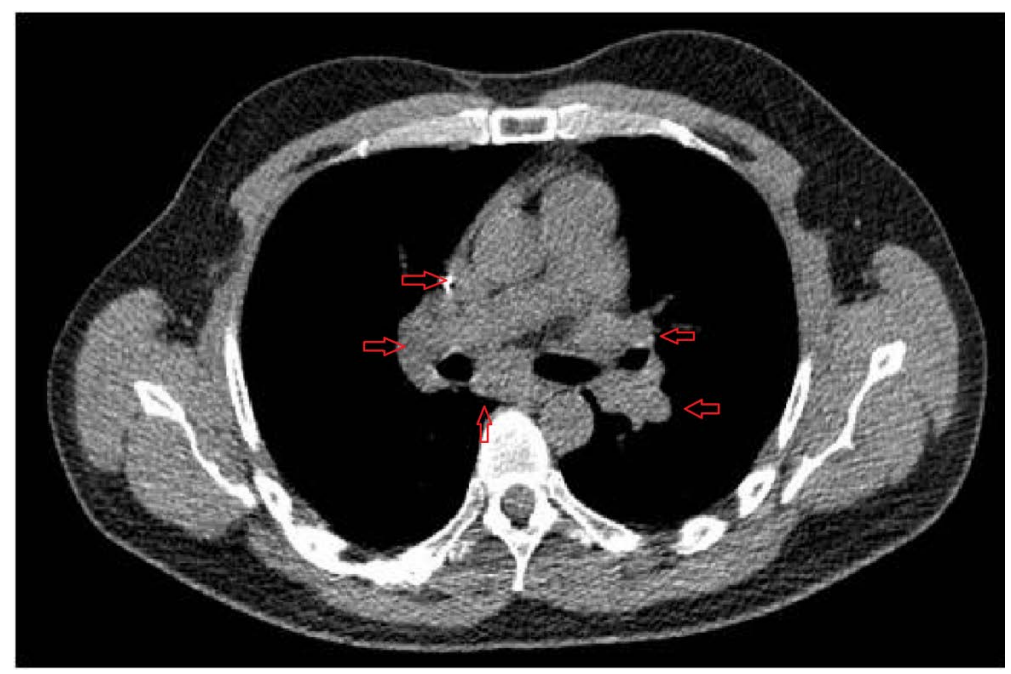

Figure 2. CT scan of the chest showing bilateral lymph nodes enlargement (red arrows) in the mediastinum.

enlargement (red arrows) in the mediastinum). Gallium $\left({ }^{68} \mathrm{Ga}\right)$ PET scan indicated multiple foci of increased uptake on mediastinum and axillae, highly suspicious to Sarcoidosis with Cardiac Involvement (Figure 3-Gallium PET scan showed multiple foci of increased uptake on mediastinum and axillae (black arrows)).The Final diagnosis of Sarcoidosis was established by mediastinal lymph node biopsy showing non-caseating epithelioid cell granulomas of sarcoidosis (Figure 4-Mediastinal Lymph node biopsy indicate noncaseating epithelioid cell granulomas (center of image) of sarcoidosis (H \& E staining)).

\subsection{Case II}

A 58-year-old female who was recently diagnosed with pulmonary Sarcoidosis based on chest CT finding indicated bihilar and mediastinal lymph nodes enlargement (Figure 5-CT scan of the chest showing bihilar and mediastinal 


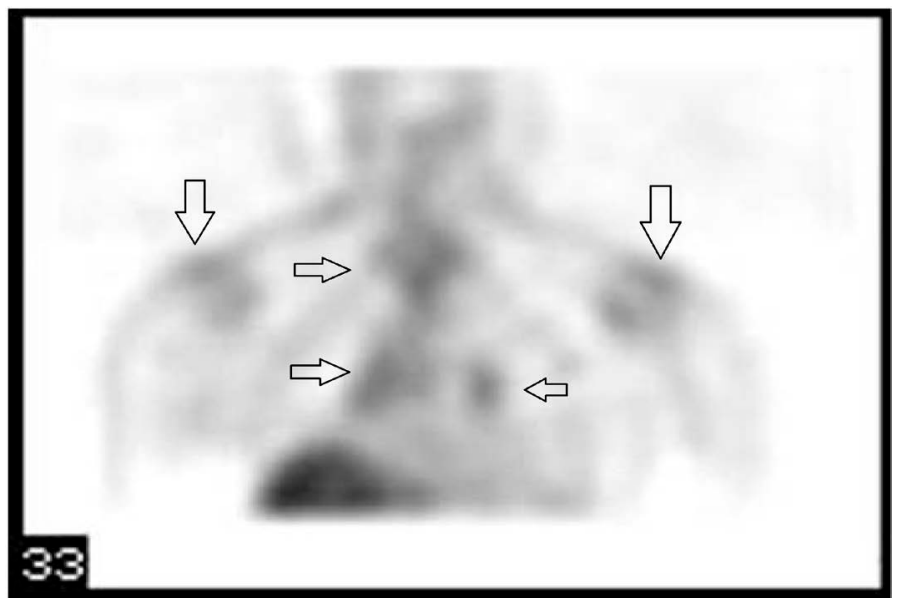

Figure 3. Gallium PET scan showed multiple foci of increased uptake on mediastinum and axillae (black arrows).

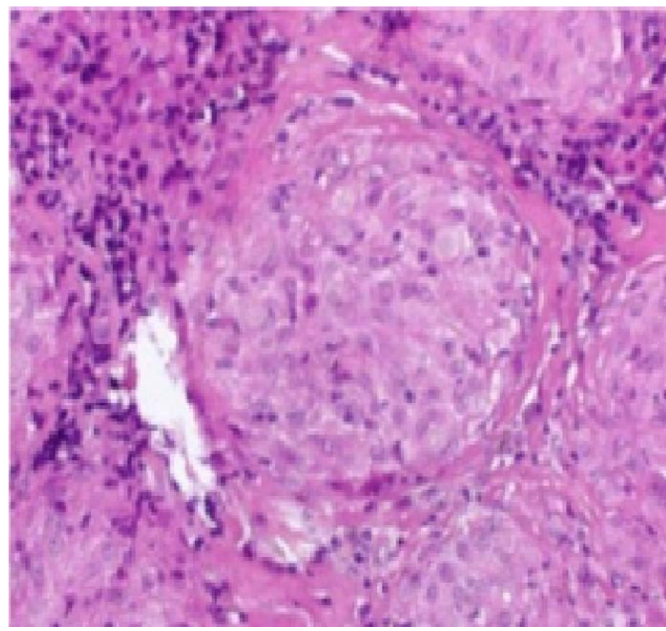

Figure 4. Mediastinal Lymph node biopsy indicate noncaseating epithelioid cell granulomas (center of image) of sarcoidosis (H \& E staining).

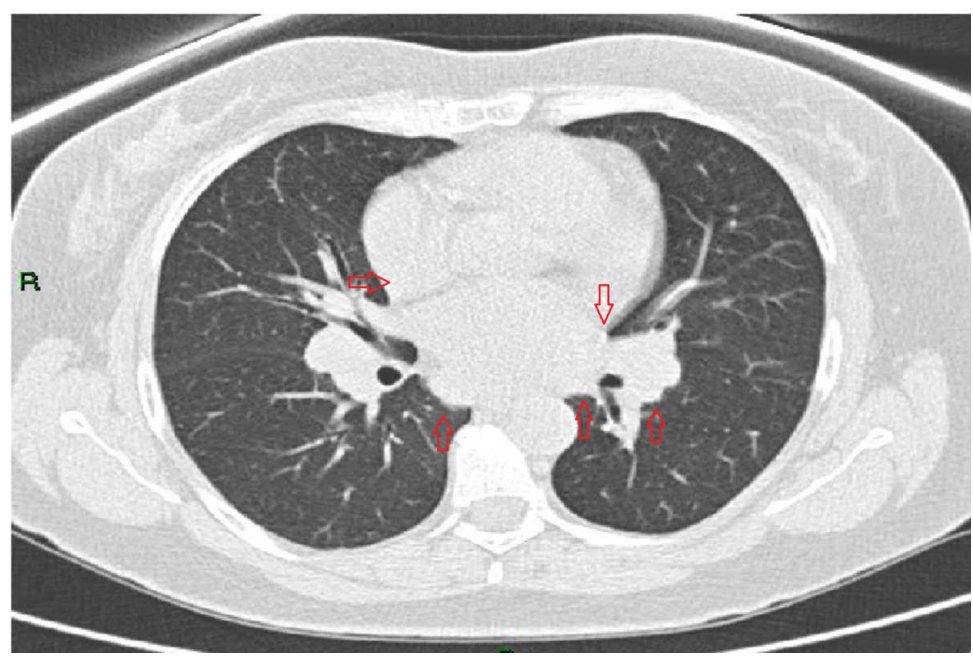

Figure 5. CT scan of the chest showing bihilar and mediastinal lymph nodes enlargement (red arrows). 


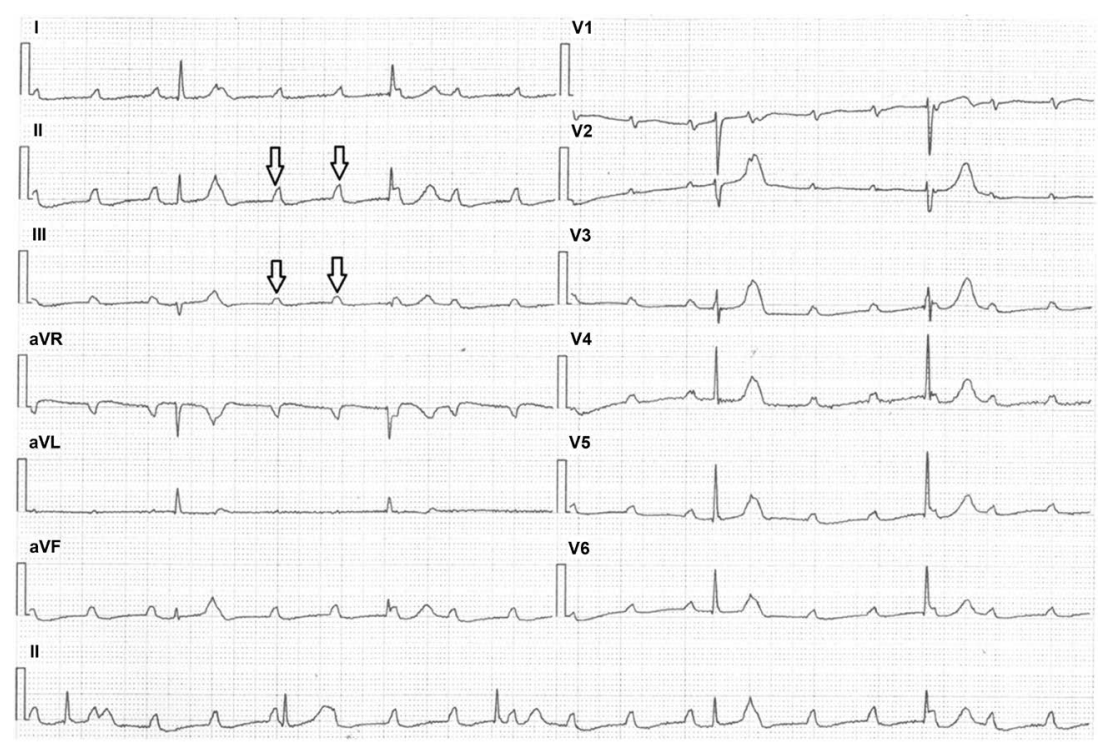

Figure 6. Leads ECG show multiple non-conducted P waves (black arrows) with ventricular escape rhythm indicate complete atrioventricular block.

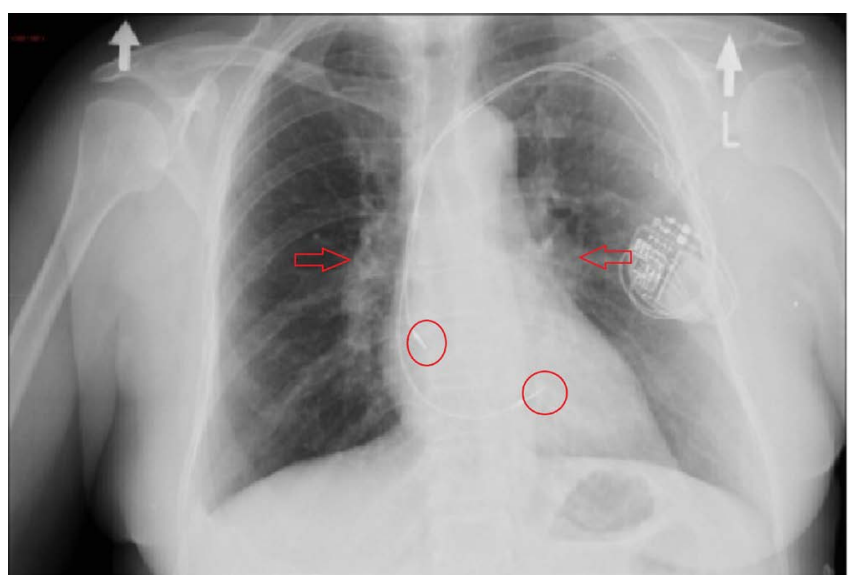

Figure 7. Chest X-ray image show bihilar lymph nodes enlargement (red arrows) and dual camber pacemaker with leads in right atria \& ventricle (red circles).

lymph nodes enlargement (red arrows)) and high level of serum Angiotensin converting enzyme (ACE). The patient brought to emergency room after complaining on prolonged fatigue and dizziness and recurrent episodes of pre-syncope for the last several weeks. Initial 12 leads ECG revealed complete atrioventricular block (Figure 6-12 leads ECG show multiple non-conducted P waves (black arrows) with ventricular escape rhythm indicate complete atrioventricular block). Initial lab results showed modest increase in cardiac enzymes but near normal coronary angiography dismissed ischemic cause. On Electrophysiological study there was no evidence of inducible tachyarrhythmia which eventually lead us to suspect cardiac involvement of Pulmonary Sarcoidosis. Patients was treated by a permanent pacemaker (Figure 7-Chest X-ray image show bihilar lymph nodes enlargement (red arrows) and dual camber pacemaker with leads in right atria \& ventricle (red circles)). Follow up revealed no further episodes. 


\section{Summary and Conclusions}

We describe two patients with Cardiac Sarcoidosis, initially presenting with a high degree of AV block requiring pacemaker therapy. The diagnosis of CS for the first patient was established during recent events. For the second case cardiac involvement in patient with pulmonary sarcoidosis was diagnosed due to new conduction disturbances.

Our recommendation, supported by the literature, is to preform early screening for cardiac involvement on patients with Sarcoidosis taking a detailed clinical history, a 12-lead ECG and echocardiogram. If necessary other modalities such as Cardiac MRI may also be performed.

\section{Conflicts of Interest}

The authors declare no conflicts of interest regarding the publication of this paper.

\section{References}

[1] Newman, L.S., Rose, C.S. and Maier, L.A. (1997) Sarcoidosis. The New England Journal of Medicine, 336, 1224-1234. https://doi.org/10.1056/NEJM199704243361706

[2] Fauci, A., Kasper, D., Hauser, S., Jameson, J. and Loscalzo, J. (2011) Harrison's Principles of Internal Medicine. 18 Edition, McGraw-Hill Professional, New York.

[3] Matsui, Y., Iwai, K., Tachibana, T., et al. (1976) Clinicopathological Study on Fatal Myocardial Sarcoidosis. Annals of the New York Academy of Sciences, 278, 455-469. https://doi.org/10.1111/j.1749-6632.1976.tb47058.x

[4] Morimoto, T., Azuma, A., Abe, S., Usuki, J., Kudoh, S., Sugisaki, K., Oritsu, M. and Nukiwa, T. (2008) Epidemiology of Sarcoidosis in Japan. European Respiratory Journal, 31, 372. https://doi.org/10.1183/09031936.00075307

[5] Rybicki, B.A., Major, M., Popovich Jr., J., Maliarik, M.J. and Iannuzzi, M.C. (1997) Racial Differences in Sarcoidosis Incidence: A 5-Year Study in a Health Maintenance Organization. American Journal of Epidemiology, 145, 234-241. https://doi.org/10.1093/oxfordjournals.aje.a009096

[6] Siltzbach, L.E., James, D.G., Neville, E., et al. (1974) Course and Prognosis of Sarcoidosis around the World. American Journal of Medicine, 57, 847-852. https://doi.org/10.1016/0002-9343(74)90160-0

[7] Milman, N. and Selroos, O. (1990) Pulmonary Sarcoidosis in the Nordic Countries 1950-1982: Epidemiology and Clinical Picture. Sarcoidosis, 7, 50-57.

[8] Sekhri, V., Sanal, S., DeLorenzo, L.J., Aronow, W.S. and Maguire, G.P. (2011) Cardiac Sarcoidosis: A Comprehensive Review. Archives of Medical Science, 7, 546-554. https://doi.org/10.5114/aoms.2011.24118

[9] Baughman, R.P., Teirstein, A.S., Judson, M.A., Rossman, M.D., Yeager, H., Bresnitz, E.A., DePalo, L., Hunninghake, G., Iannuzzi, M.C., Johns, C.J., McLennan, G., Moller, D.R., Newman, L.S., Rabin, D.L., Rose, C., Rybicki, B., Weinberger, S.E., Terrin, M.L., Knatterud, G.L. and Cherniak, R. (2001) Clinical Characteristics of Patients in a Case Control Study of Sarcoidosis. American Journal of Respiratory and Critical Care Medicine, 164, 1885-1889. https://doi.org/10.1164/ajrccm.164.10.2104046

[10] Pietinalho, A., Hiraga, Y., Hosoda, Y., Lofroos, A.B., Yamaguchi, M. and Selroos, O. 
(1995) The Frequency of Sarcoidosis in Finland and Hokkaido, Japan: A Comparative Epidemiological Study. Sarcoidosis, 12, 61-67.

[11] Habersberger, J., Manins, V. and Taylor, A.J. (2008) Cardiac Sarcoidosis. Internal Medicine Journal, 38, 270-277. https://doi.org/10.1111/j.1445-5994.2007.01590.x

[12] Sharma, O.P. (2003) Diagnosis of Cardiac Sarcoidosis an Imperfect Science, a Hesitant Art. Chest, 123, 18-19. https://doi.org/10.1378/chest.123.1.18

[13] Burstow, D.J., Tajik, A.J., Bailey, K.R., DeRemee, R.A. and Taliercio, C.P. (1989) Two-Dimensional Echocardiographic Findings in Systemic Sarcoidosis. American Journal of Cardiology, 63, 478-482. https://doi.org/10.1016/0002-9149(89)90323-8

[14] Dubrey, S.W., Bell, A. and Mittal, T.K. (2007) Sarcoid Heart Disease. Postgraduate Medical Journal, 83, 618-623. https://doi.org/10.1136/pgmj.2007.060608

[15] Tachibana, T., Iwai, K. and Takemura, T. (1991) Study on the Cause of Death in Patients with Sarcoidosis in Japan [Abstract]. XII World Congress on Sarcoidosis, Kyoto, Japan, 8 September 1991.

[16] Iannuzzi, M.C., Rybicki, B.A. and Teirstein, A.S. (2007) Sarcoidosis Medical Progress. The New England Journal of Medicine, 357, 2153-2165. https://doi.org/10.1056/NEJMra071714

[17] Mori, M., Hanon, S. and Rachko, M. (2007) Case Report: Cardiac Sarcoidosis Presenting with Ventricular Arrhythmias: Case Report and Review of the Literature. International Journal of Cardiology, 120, e21-e23. https://doi.org/10.1016/j.ijcard.2007.04.036

[18] Tadamura, E., Yamamuro, M. and Kubo, S., et al. (2005) Effectiveness of Delayed Enhanced MRI for Identification of Cardiac Sarcoidosis: Comparison with Radionuclide Imaging. AJR. American Journal of Roentgenology, 185, 110-115. https://doi.org/10.2214/ajr.185.1.01850110 